\title{
De gestante a mãe: o veneno em um relato de ideação suicida
}

\author{
From pregnant to mother: the poison in a report case of suicidal idea \\ De embarazada a madre: el veneno en un caso de ideación suicida \\ Yasmine Rocha Martins ${ }^{1 *}$.
}

\begin{abstract}
RESUMO
Objetivo: Esse artigo buscou investigar os aspectos psicológicos que permeiam a ideação suicida em gestantes e puérperas. Método: $O$ procedimento se compõe de psicoterapia breve psicanalítica, estabelecendo-se o foco terapêutico e a brevidade do tratamento. Por meio da interpretação, pretendeu-se levar o paciente a ter melhor percepção de sua história e dos respectivos mecanismos defensivos ou psicodinâmicos que prevalecem em seu inconsciente. O estudo se deu no Hospital do Servidor Público Estadual de São Paulo, com a devida aprovação do comitê de ética. Resultados: A análise do caso de ideação suicida na gestação foi pensada a luz da psicanálise freudiana. Conclusão: Diante do caso clinico apresentado, fica evidenciado que lutos repetidos e não elaborados trouxeram intensa desesperança e desinvestimento da vida. As perdas são percebidas como rejeições. O suicídio é cada vez mais um fenômeno social que tem relevância em todos os níveis da sociedade, trabalhos que abordem o tema servem de meios para conhecer melhor os meandros da ideação suicida.
\end{abstract}

Palavras-chave: Ideação Suicida, Gestantes e puérperas, Maternidade.

\begin{abstract}
Objective: This article aimed to investigate the psychological aspects that pervade suicidal ideation in pregnant women and postpartum women. Method: The procedure consists of brief psychoanalytic psychotherapy, establishing the therapeutic focus and the brevity of the treatment. Through interpretation, it was intended to lead the patient to have a better perception of their history and the respective defensive or psychodynamic mechanisms that prevail in their unconscious. The study was conducted at the State Public Hospital of São Paulo, with the approval of the ethics committee. Results: The analysis of the case of suicidal ideation in gestation was thought in the light of Freudian psychoanalysis. Conclusion: In view of the clinical case presented, it is evident that repeated and unprocessed mourning brought intense hopelessness and disinvestment of life. The losses are perceived as rejections. Suicide is increasingly a social phenomenon that has relevance in all levels of society, works that approach the subject serve as means to know better the intricacies of suicidal ideation.
\end{abstract}

Key words: Suicidal ideation, Pregnant and puerperal, Maternity.

\section{RESUMEN}

Objetivo: Este artículo tuvo como objetivo investigar los aspectos psicológicos que prevalecen en la ideación suicida en mujeres embarazadas y en posparto. Método: El procedimiento consiste en una breve psicoterapia psicoanalítica, que establece el enfoque terapéutico y la brevedad del tratamiento. A través de la interpretación, se pretendía llevar al paciente a tener una mejor percepción de su historia y los respectivos mecanismos defensivos o psicodinámicos que prevalecen en su inconsciente. El estudio se realizó en el Hospital Público Estatal del Hospital de São Paulo, con la aprobación del comité de ética. Resultados: El análisis del caso de la ideación suicida en gestación se pensó a la luz del psicoanálisis freudiano. Conclusión: En vista del caso clínico presentado, es evidente que el luto repetido y no procesado trajo intensa desesperanza y desinversión de la vida. Las pérdidas se perciben como rechazos. El suicidio es cada vez más un fenómeno social que tiene relevancia en todos los niveles de la sociedad, las obras que abordan el tema sirven como medios para conocer mejor las complejidades de la ideación suicida.

Palabras clave: Ideación suicida, Gestante y puerperal, Maternidad.

1Instituto de Assistência Médica ao Servidor Público Estadual de São Paulo (IAMSPE), São Paulo - SP.

*E-mail: yasmine.psicooncologia@yahoo.com.br

SUBMETIDO EM: 7/2019

ACEITO EM: 7/2019

PUBLICADO EM: 9/2019

REAS/EJCH | Vol. Sup.33 | e1279 | DOI: https://doi.org/10.25248/reas.e1279.2019 Página 1 de 5 


\section{INTRODUÇÃO}

O suicídio é comumente visto como um ato intencional de acabar com a própria vida. Além do fato nefasto de finalizar com a energia vital própria também pode ser visto desde um posicionamento subjetivo, até um quadro psicopatológico. Segundo Medeiros MV (2010) A história de Sócrates nos revela o suicídio como um dever moral, uma escolha que se relaciona a sua fidelidade à própria ideologia.

Sócrates foi um filosofo ateniense da Grécia Antiga, tornou-se renomado pela sua contribuição à ética, viveu em uma época onde a verdade era dita pela classe dominante e pensadora. Seus ensinamentos eram passados de maneira gratuita. Segundo Goto R (2010) tais ensinamentos eram de conteúdo caríssimo, potencialmente começaram a incomodar a classe dominante.

Sendo assim, Sócrates foi integrado ao gerenciamento da guerra de Peloponeso, pela sua grande habilidade de persuasão e de fazer com que as pessoas o seguissem. Segundo Mondolfo R (1965) ao final da guerra com o intuito de salvar os soldados ainda vivos, mesmo contra a lei, abandona o corpo dos mortos no campo de batalha e retorna com seus soldados para Atenas. Ao chegar, é preso. Convence as autoridades que seria mais inteligente proteger a vida dos soldados vivos do que colocar em risco a vida e força de trabalho dos mesmos, por corpos estilhaçados pela guerra. Dessa forma atinge a liberdade.

Trinta anos de liberdade se passaram quando foi preso sob a acusação de, não seguir e nem acreditar nos costumes gregos, de unir-se a deuses do mal e de corromper jovens com suas ideias. Em sua defesa, evidencia como as acusações eram contraditórias, mesmo assim o tribunal o condenou ao exílio, a morte o tornaria mártir. Segundo Spinelli M (2006) após receber sua sentença, Sócrates proferiu que os cidadãos deixassem duas escolhas a ele: uma, era viver sem poder ensinar e outra desconhecida, referiu-se a morte. Pois bem, ele escolheria a morte, ou melhor o desconhecido. Ingeriu cicuta e diante dos amigos, morreu por envenenamento. Em um impulso escolheu sua verdade, a morte para ele serviu de liberdade, foi uma possibilidade de não se prender a uma situação de sofrimento e restrição. Era inconcebível viver no corpo físico sem passar adiante suas ideias, esse estado não era vida, não tinha potência, não atingia sua essência.

Os indivíduos que pensam em colocar um fim a vida, passam ou passaram por intensa tristeza, perdas ou desilusões e não veem mais sentido em seguir. Segundo Prieto D e Tavares M (2005) conectam-se a um estado inorgânico e a morte pode representar uma fuga, ou a possibilidade de um novo recomeço, ou até mesmo a finalização do sofrimento.

Simbolicamente o desejo impulsiona os sujeitos, faz os mesmos viverem ou morrerem. Pode ser um desejo positivo, que leva o sujeito para frente, que o faz ambicionar, ou um desejo negativo, destrutivo, que leva a desesperança. Segundo Schlösser A et al (2014) o veneno que leva ao suicídio é escolhido ou não de acordo com as motivações e esperanças do sujeito em um impulso, o veneno que cada um escolhe pode ser mortal ou vital.

Botega NJ et al (2009) relatou em seu estudo sobre ideação, plano e tentativa de suicídio, que as mulheres apresentam maior frequência em pensamentos suicidas, aquelas entre 30 a 44 anos, espíritas e as de maior renda. Há prevalência nos relatos de mulheres com mais de uma tentativa, e aquelas que escolheram ingerir medicamentos em excesso. Geralmente consiste no resultado de atos impulsivos e sem planejamento.

As perdas podem ser diversas, ainda segundo Freud S (1917) há perdas absolutas, relacionadas a morte, separações de alguém, ou até mesmo exílio, ou desistência. Não apenas relacionadas a pessoas, também podem ser perdas financeiras, posição social ou patrimônio. Na concepção freudiana, as características do processo de luto são a inibição e o estreitamento do ego e não se trata de um fenômeno patológico, é um momento no qual a libido investida anteriormente no objeto de amor é retirada. Após determinado tempo o luto é concluído deixando assim o ego livre, segundo Freud S (1917).

O objetivo foi investigar os aspectos psicológicos que permeiam a ideação suicida em gestantes e puérperas, detectar fatores emocionais na história do sujeito que levam a ideação suicida e avaliar os aspectos intradinâmicos da ideação suicida. 


\section{MÉTODOS}

Trata-se de uma pesquisa qualitativa, obtiveram-se dados descritivos mediante contato interativo e direto com o objeto de estudo. Assim sendo, pretendeu-se compreender os fenômenos com o relato da participante da pesquisa visando à situação em questão, e com isso conceituar uma interpretação dos fenômenos estudados. A pesquisa foi devidamente aprovada pelo comitê de ética.

O estudo de caso contém a identificação da demanda, posicionamento clinico e tratamento do tema. Apresentado em um texto analítico, fundamentado na organização e interpretação dos dados, conforme objetivos estabelecidos. Os dados são pensados a partir de formas de raciocínio, no caso, de raciocínio indutivo, partindo da experiência relatada no caso e observações em sua particularidade para se chegar a um princípio geral.

O estudo seguiu no ambulatório de psicologia do Hospital do Servidor Público Estadual (HSPE) durante o aprimoramento em Psicologia Hospitalar da pesquisadora. O sujeito de pesquisa se constitui de uma mulher de 25 a 35 anos que apresenta ou apresentou ideação suicida na fase gestacional ou puérpera. $O$ critério de inclusão é ter passado por planos suicidas, não ter sido submetida a atendimento psicológico e ser puérpera ou gestante. O critério de exclusão é não ter passado por ideação suicida, já estar em atendimento psicológico e não ser puérpera ou gestante.

Após a seleção da participante de acordo com os critérios acima, a paciente foi chamada para receber o convite para participar da pesquisa. Em uma conversa dialogada a pesquisadora explicou sobre o tema da pesquisa e quais os objetivos, métodos e possíveis riscos. A pesquisadora deixou claro que a paciente pode aceitar ou recusar, sem prejuízo nenhum ao seu atendimento no ambulatório de psicologia.

O procedimento se compõe de psicoterapia breve psicanalítica, que segundo Ramadam ZB (2007) tem como essência o foco terapêutico e a brevidade do tratamento. O terapeuta tem como meta um conflito central, levantado nas fases de entrevista preliminares. A demanda desdobra-se em questões de difícil adaptação para a paciente.

Através da interpretação, o psicoterapeuta leva o paciente a ter melhor percepção de sua história e quais mecanismos usou para lidar com ela, o tempo limitado de tratamento ajuda o paciente a se mobilizar e se envolver com suas próprias questões de maneira mais implicada ou comprometida.

Ainda segundo Ramadam ZB (2007) a psicoterapia breve é indicado para aqueles que não tem comprometimentos psíquicos graves, mas tiveram seu equilibro psíquico alterado por períodos de luto, ansiedade, tristeza entre outros. Refere-se a uma instabilidade mental que levou a desajustes nos relacionamentos interpessoais e no equilíbrio somático e psíquico.

Gillieron E (1983) ressalta a melhora do paciente, quanto ao novo olhar que o mesmo vai ganhando durante o processo, quanto à conscientização de seus mecanismos inconscientes que interferem na resolução de seus conflitos.

Observa-se que se expressar livremente contribui para que o sujeito se conheça melhor, conheça com riqueza de detalhes o que o faz sofrer, traz para o consciente aquilo que manteve recalcado. $\mathrm{E}$ assim se ganha a opção de elaborar seus conteúdos e dar novo significado as suas vivências.

Antes de iniciar a psicoterapia breve propriamente dita, a pesquisadora realizou algumas entrevistas preliminares para conhecimento da demanda da paciente.

Freud S (1913) cita que antes da análise, é preciso um momento para traçar um caminho para que o analista possa cumprir sua promessa de cura. Esse período é o começo do tratamento, analisando-o pode criar um vínculo com o terapeuta, que é propulsor para o tratamento. É onde a confiança se estabelece e o indivíduo confia no auxílio do terapeuta, que supõe saber de algo sobre o sofrimento dele e pode tratá-lo.

Os procedimentos de psicoterapia breve na instituição comportam doze sessões para finalização do processo. Todo o processo oferece risco mínimo ao paciente, apenas riscos intrínsecos ao ambiente. 


\section{RESULTADOS}

Considerando o complexo de Édipo, o amor e desejo pelo progenitor do sexo oposto e hostilidade para com o progenitor do mesmo sexo, a criança por volta de três a cinco anos começa a passar por essa fase, desaparece com o complexo de castração; a menina reconhece a figura materna como um obstáculo à realização de seus desejos. Nasio JD (2007) afirma que a menina abandona o investimento feito no pai e evolui para uma identificação com a mãe, condição que the permite outras escolhas objetais e novas identificações.

No processo de castração a paciente referida no estudo passou por um acontecimento importante, na qual o progenitor do sexo oposto, seu pai, traiu sua mãe. A paciente inconscientemente leva a traição como se fosse para si mesma e rompe com seu pai. Mais adiante, na vida adulta, permanece em um relacionamento por alguns anos e uma traição acontece, remetendo a sua infância e a traição de seu pai. Fato que em seu psiquismo se constitui um trauma.

Trauma segundo Freud S (1910) são experiências emocionais que provocam afetos de medo, susto, vergonha. Ideias que o aparelho psíquico tem dificuldade em resolver por meio de pensamentos associativos e racionais. A paciente em questão tem histórico de intensas e diversas perdas, se mostra enlutada em algumas ocasiões devido a mortes e também por perdas de relacionamentos amorosos ou de amigos.

Suas perdas são percebidas como rejeições, mesmo em casos de morte, a paciente se sente rejeitada e se coloca como responsável pela situação negativa. Aproxima-se da morte e acredita que a leva para os outros. Maior motivo para a mesma escolher o exílio e tristeza.

O acúmulo de percepções negativas faz com que a mesma desista, privilegiando sua pulsão autodestrutiva. Percebe a morte como um fim do sofrimento e mesmo grávida considera o suicídio, após o nascimento de seu bebê, permanece com a ideação suicida.

Suas filhas servem de motivação e a paciente não concretiza o suicídio, entretanto se encontra em risco eminente de seguir suas idéias suicidas. Mediante seu relato a repetição do abandono e rejeição ainda são bastante presentes em seu psiquismo. Entretanto vê o acompanhamento psicológico como suporte.

\section{DISCUSSÃO}

Marie $L$ (1981) ressalta que historicamente a mulher tem restrições a sua sexualidade e também a sua relação com o meio, seu ramo social. Entretanto a maternidade e suas nuances sofreram intensa influência, ou seja, a mulher tem desenvolvido nessa época sua função materna como única. Com a precariedade de outras atividades para se implicar, com os anos o quadro mudou e a mulher ganhou poder está cada vez mais liberta para suas próprias escolhas.

Os relatos das pacientes de Marie $L$ (1981) são de que sentiram uma exímia felicidade na segunda metade da gravidez; uma felicidade serena que não teriam sentido desde então. Mas que a paz e felicidade é perturbada próximo do final da gestação.

O filho começa a tornar-se algo dentro de uma realidade tangível, se distancia a ideia de um filho que ela apenas sente, que desconhece. O temor do parto, da dor e do sofrimento ficam mais evidentes no psiquismo, mesmo com o perigo físico estar diminuído pela obstetrícia moderna a parturiente teme o parto. Entretanto Marie $L$ (1981) afirma que a angústia diante do parto tem raízes inconscientes, ou seja, a mulher se sente em um exame final, irá verificar se seu interior está intacto, se sua obra, o bebê, está bem, e se ela não prejudicou o filho. A angústia do parto é, a rememoração da angústia mais antiga, a separação da mãe.

A autora ainda relata que após observações, verificou que aquelas mulheres que conviveram com mães que relatavam ter tido partos difíceis, afirmam que tiveram partos angustiantes e cheio de dor. Os transtornos psicológicos na gravidez são múltiplos, entretanto na maioria das vezes se trata de uma rejeição da criança, seja por uma condição econômica, social ou por falta de interesse e amor no filho. Por diversas vezes a mulher reproduz sua própria situação infantil, sua relação com sua própria mãe. Gutierrez DM (2011) afirma que esse fenômeno ocorre pela identificação que a mãe tem com seu bebê. 
Como verificado no trabalho, o suicídio se trata de um ato intencional de finalizar com a própria vida, tendo em vista um contínuo estado de angústia e/ou tristeza. Vê-se como referência a história de Sócrates, filósofo, que em sua concepção preferiu o suicídio em detrimento de ferir sua própria ideologia. Verificou-se portanto o fato de o auto assassinato servir como um posicionamento subjetivo. Um ato que finaliza sua própria energia vital. À análise do caso clínico foi pensada a luz da psicanálise freudiana, a partir de considerar a mulher como sujeito de estudo, sua condição e psicopatologias cotidianas.

Diante do caso clinico apresentado, fica evidenciado que lutos repetidos e não elaborados trouxeram para a paciente intensa desesperança e desinvestimento da vida, a mesma percebia a morte como a finalização do sofrimento. Suas perdas são percebidas como rejeições, mesmo em caso de morte de pessoas próximas. A paciente se sente rejeitada e se coloca como responsável pela situação negativa. Se aproxima da morte, e acredita que a leva para os outros. Maior motivo para a mesma escolher o exílio e tristeza.

O relato do caso em conjunto com a articulação teórica da presente pesquisa se faz um instrumento relevante para a equipe de saúde abranger seu conhecimento. De maneira que o conhecimento inflado pode melhorar as condições de tratamento e prevenção, para aqueles que nutrem ideações suicidas.

\section{CONSIDERAÇÕES FINAIS}

O suicídio é cada vez mais um fenômeno social que tem relevância em todos os níveis da sociedade, principalmente entre as gestantes. Ludo mal resolvido e intensa vivência emocional por estar grávida pode deixar as mulheres para vulneráveis para ideação suicida. A psicanálise se faz um importante recurso para tais mulheres.

\section{REFERÊNCIAS}

1. BOTEGA NJ, MARÍN-LEÓN L et al. Prevalências de ideação, planos e tentativas de suicídio: um inquérito populacional em Campinas SP. Cadernos de Saúde Pública, 2009; 25(12): 2632-2638.

2. MEDEIROS MV. Sócrates: a vida e a morte pela filosofia. Etic-encontro de iniciação científica, 2010; 6(6): 21-36.

3. FREUD S. Sobre o início do tratamento. Edição Standard Brasileira das Obras Psicológicas Completas de Sigmund Freud Rio de Janeiro: Imago, 1996, p.137-158. (Originalmente publicado em 1913).

4. FREUD S. Cinco lições de psicanálise. Edição Standard Brasileira das Obras Completas de Sigmund Freud, vol. XIX. Rio de Janeiro: Imago (Originalmente publicado em 1910)

5. GOTO R O cidadão Sócrates e o filosofar numa democracia. Pro-Posições, 2010.

6. GILLIĖRON E. As Psicoterapias Breves. Rio de Janeiro: Jorge Zahar, 1983.

7. GUTIERREZ DM; PONTES KD. Vínculos mãe-filho: reflexões históricas e conceituais à luz da psicanálise e da transmissão psíquica entre gerações. Revista do NUFEN, 2011;3 (2):3-24

8. MONDOLFO R. Sócrates. Editora: Mestre Jou, 1965.

9. NASIO JD. Édipo: o complexo do qual nenhuma criança escapa. Zahar, 2007.

10. PINEAU G. As histórias de vida como artes formadoras da existência. Tempos, narrativas e ficções: a invenção de si. Porto Alegre: Edipucrs, p. 41-59, 2006.

11. PRIETO D, TAVARES M. Fatores de risco para suicídio e tentativa de suicídio: incidência, eventos estressores e transtornos mentais. J. bras. psiquiatr, p. 146-154, 2005.

12. LANGER M. Maternidade e sexo. Porto Alegre, Artes Médicas, 1951

13. SCHLÖSSER A, ROSA GF, MORE CL. Revisão: comportamento suicida ao longo do ciclo vital. Temas em Psicologia, 2014;22 (1): 133-145

14. SPINELLI M. Questões Fundamentais da Filosofia Grega. São Paulo: Loyola, 2006, 45-186.

15. RAMADAM ZB. Psicoterapia psicanalítica breve. Revista Psiquiatria Clínica, São Paulo, 2007: 34 (1): 50-51. 